\title{
MMP-I serum levels predict coronary atherosclerosis in humans
} Michael Lehrke* ${ }^{* 1}$, Martin Greif ${ }^{\dagger 2}$, Uli C Broedl1 ${ }^{1}$, Corinna Lebherz ${ }^{2}$, Rüdiger P Laubender ${ }^{3}$, Alexander Becker ${ }^{2}$, Franz von Ziegler ${ }^{2}$, Janine Tittus ${ }^{2}$, Maximilian Reiser ${ }^{4}$, Christoph Becker ${ }^{4}$, Burkhard Göke ${ }^{1}$, Gerhard Steinbeck ${ }^{2}$, Alexander W Leber ${ }^{2}$ and Klaus G Parhofer ${ }^{1}$

\author{
Address: ${ }^{1}$ Department of Internal Medicine II, University of Munich, Munich, Germany, ${ }^{2}$ Department of Internal Medicine I, University of Munich, \\ Munich, Germany, ${ }^{3}$ Institute for Medical Informatics, Biometry and Epidemiology (IBE), University of Munich, Munich, Germany and \\ ${ }^{4}$ Department of Radiology, University of Munich, Munich, Germany \\ Email: Michael Lehrke* - Michael.Lehrke@med.uni-muenchen.de; Martin Greif - Martin.Greif@med.uni-muenchen.de; \\ Uli C Broedl - Uli.Broedl@med.uni-muenchen.de; Corinna Lebherz - Corinna.Lebherz@med.uni-muenchen.de; \\ Rüdiger P Laubender - laubend@ibe.med.uni-muenchen.de; Alexander Becker - Alexander.Becker@med.uni-muenchen.de; Franz von \\ Ziegler - Franz.Ziegler@med.uni-muenchen.de; Janine Tittus - Janine.Tittus@med.uni-muenchen.de; \\ Maximilian Reiser - Dekan.Reiser@med.uni-muenchen.de; Christoph Becker - Christoph.Becker@med.uni-muenchen.de; \\ Burkhard Göke - Burkhard.Goeke@med.uni-muenchen.de; Gerhard Steinbeck -Gerhard.Steinbeck@med.uni-muenchen.de; \\ Alexander W Leber - dr_leber@gmx.de; Klaus G Parhofer - Klaus.Parhofer@med.uni-muenchen.de \\ * Corresponding author †Equal contributors
}

Published: 14 September 2009

Cardiovascular Diabetology 2009, 8:50 doi:10.1/86/1475-2840-8-50

This article is available from: http://www.cardiab.com/content/8/I/50

(C) 2009 Lehrke et al; licensee BioMed Central Ltd.

This is an Open Access article distributed under the terms of the Creative Commons Attribution License (http://creativecommons.org/licenses/by/2.0), which permits unrestricted use, distribution, and reproduction in any medium, provided the original work is properly cited.
Received: I July 2009

Accepted: 14 September 2009

Background: Myocardial infarction results as a consequence of atherosclerotic plaque rupture, with plaque stability largely depending on the lesion forming extracellular matrix components. Lipid enriched non-calcified lesions are considered more instable and rupture prone than calcified lesions. Matrix metalloproteinases (MMPs) are extracellular matrix degrading enzymes with plaque destabilisating characteristics which have been implicated in atherogenesis. We therefore hypothesised MMP-I and MMP-9 serum levels to be associated with non-calcified lesions as determined by $\mathrm{CT}$-angiography in patients with coronary artery disease.

Methods: 260 patients with typical or atypical chest pain underwent dual-source multi-slice CTangiography $(0.6-\mathrm{mm}$ collimation, $330-\mathrm{ms}$ gantry rotation time) to exclude coronary artery stenosis. Atherosclerotic plaques were classified as calcified, mixed or non-calcified.

Results: In multivariable regession analysis, MMP-I serum levels were associated with total plaque burden (OR: I.37 (Cl: I.02-I.85); $\mathrm{p}<0.05)$ in a model adjusted for age, sex, BMI, classical cardiovascular risk factors, hsCRP, adiponectin, pericardial fat volume and medication. Specification of plaque morphology revealed significant association of MMP-I serum levels with non-calcified plaques (OR: I. 16 (Cl: I.0-I.34); $=0.05$ ) and calcified plaques (OR: I.22 (Cl: I,03-I.45); $<$ < 0.05) while association with mixed plaques was lost in the fully adjusted model. No associations were found between MMP9 serum levels and total plaque burden or plaque morphology.

Conclusion: MMP-I serum levels are associated with total plaque burden but do not allow a specification of plaque morphology. 


\section{Introduction}

Myocardial infarction is an acute pathological event which is caused by the rupture of a chronically formed atherosclerotic lesion. The process of atherosclerosis is initiated by the entrapment of modified LDL particles in the subendothelial space of the vessel wall, which causes the infiltration of immune cells, especially macrophages and subsequent foam cell formation. Proliferation of vascular smooth muscle cells (VSMC) and the deposition of extracellular matrix components result in the progression to more advanced lesions, stigmatized by a fibrous cap overlaying a lipid enriched atherosclerotic core [1]. Plaque rupture mostly occurs in the plaques' shoulder region, which is exposed to high tangential shear stress. The biochemical strength of the fibrous cap thereby depends on its extracellular matrix composition with fibrillar collagen, especially type I and III, providing structural stability by cross linkage [2].

Intravascular ultrasound (IVUS) and CT angiography do now allow the in-vivo detection of outward directed nonstenosing lesions in addition to the characterisation of plaque morphology. Lipid enriched, non-calcified lesions are primarily detected in the coronary system of patients presenting with unstable angina, suggesting a high rupture susceptibility of these plaques, while fibrous and calcified lesions dominate in patients presenting with stable angina [3-6]. This concept is supported by autopsy studies demonstrating impaired structural stability of soft, lipid enriched plaques in comparison to calcified lesions [7]. Consequently, non-calcified lesions were prospectively associated with higher coronary event rates [8,9].

Matrix Metalloproteinases (MMPs) are a family of extracellular matrix degrading enzymes which have been implicated in plaque destabilisation [10]. MMPs are expressed by macrophages, VSMC and endothelial cells in response to inflammatory stimuli. MMP-1 and MMP-9 are primarily detected in the vulnerable shoulder region and areas of foam cell formation in the atherosclerotic plaques $[10,11]$ where they colocalize with degraded collagen fragments [11]. While MMP-1 cleaves intact fibrillar interstitial collagen, especially type I and III, MMP-9 has prominent activity against basement membrane components including type IV collagen, laminin and elastin [12]. Consistently, polymorphisms of the MMP-1 and -9 genes were linked to complicated coronary lesions and atherosclerosis in epidemiological studies $[13,14]$.

We therefore hypothesized MMP-1 and MMP-9 serum levels to predict the presence of non-calcified, lipid enriched plaques as determined by CT angiography in a cohort of 260 patients with typical or atypical chest pain.

\section{Methods \\ Ascertainment of Subjects}

As described previously [15], 260 patients with typical or atypical chest pain underwent dual-source CT-coronary angiography for exclusion of coronary artery stenosis during a period of 20 months from March 2006 till October 2007. Study subjects were asked to complete a brief questionnaire and had blood drawn after providing written informed consent. The study protocol was approved by the Ethics Committee of the Ludwig-Maximilians-University Munich, Germany.

\section{Dual-source CT image analysis}

CT-coronary angiography was performed as described previously [15], using a Siemens Definition scanner (Siemens Medical Solutions, Forchheim, Germany). Briefly, DSCT datasets were evaluated by two independent investigators using a dedicated cardiac workstation (Siemens, Leonardo Circulation). Atherosclerotic plaques were classified as calcified, mixed or non-calcified lesions. Calcified plaques were defined as lesions with a HU value above 130 while non-calcified plaques were defined as structures clearly assignable to the vessel wall (in at least two views) with densities less than the lumen contrast. Mixed plaques where defined by $<50 \%$ plaque calcified area. The coronary tree was segmented according to the suggestions of the AHA into a 15 segment model. Each segment was further divided into a proximal and a distal segment. Each segment was then classified as containing either calcified, non-calcified, mixed or no plaque. Based on the number of diseased segments a plaque score was calculated.

Pericardial fat assessment was performed as described previously using the Volume analysis software tool of the Siemens Leonardo Circulation workstation [16].

\section{Laboratory procedures}

Blood samples were stored at $-70^{\circ} \mathrm{C}$ until analysis. Serum levels of MMP-1 and MMP-9 were determined using a commercial enzyme-linked immunosorbent assay (R\&D, Wiesbaden, Germany) following the manufacturer's instruction. Intra- and interassay coefficients of variance derived from a pooled human plasma sample measured in triplicate on each plate were $4.1 \%$ and $6.7 \%$ for MMP1 and $3.5 \%$ and $5.9 \%$ for MMP-9. Adiponectin serum levels were assessed by enzyme-linked immunosorbent assay (R\&D, Wiesbaden, Germany) as described earlier [15]. Plasma total cholesterol, LDL-cholesterol (LDL-C), HDLcholesterol (HDL-C) and triglycerides were measured by routine enzymatic methods. Determination of high sensitivity C-reactive protein (hsCRP) levels was performed at the Department of Clinical Chemistry (Campus Grosshadern, University of Munich, Germany). 


\section{Statistical Analysis}

Statistical analyses were performed using SPSS 16 and R (version 2.8.1) software. ( $\mathrm{R}$ Development Core Team (2008). R: A language and environment for statistical computing. R Foundation for Statistical Computing, Vienna, Austria. ISBN 3-900051-07-0, URL http://www.Rproject.org.)

Data are reported as proportions or median (interquartile range). Spearman correlation was perfomed as appropriate to evaluate unadjusted associations between MMP-1 or MMP-9 and other variables. A generalized linear regression model (logistic regression) based on complete cases for all covariables was used to assess the association between MMP-1 and MMP-9 serum levels with total plaque burden or the presence of calcified-, mixed- or non-calcified plaques adjusted for age, sex, body mass index (BMI), diabetes, hypertension, family history of cor- onary artery disease, smoking, LDL-C, HDL-C, triglycerides, hsCRP levels, adiponectin levels, medical treatment (statin, ACE inhibitors, angiotensin-receptor blockers, diuretics, ASS, Clopidogrel, Phenprocoumon) and pericardial adipose tissue volume.

\section{Results}

The baseline characteristic of the study sample is presented in Table 1. Representative images of different plaque morphologies as detected by CT-angiography are shown in Figure 1.

\section{Association of MMP-I and MMP-9 serum levels with cardiovascular risk factors and coronary atherosclerosis}

MMP-1 and MMP-9 were found to correlate positively to the inflammatory marker hsCRP (MMP-1, $\mathrm{r}=0.194, \mathrm{p}<$ 0.001 ; MMP-9, $\mathrm{r}=0.173, \mathrm{p}=0.005)$ and to each other $(\mathrm{r}$ $=0.269 ; \mathrm{p}<0.001$ ) (Table 2 ). In addition, positive corre-

Table I: Characteristics of the study population:

\begin{tabular}{|c|c|}
\hline Characteristics: & $n=260$ \\
\hline Age (yrs) & $63(54-69)$ \\
\hline Men (\%) & 66.8 \\
\hline \multicolumn{2}{|l|}{ Classical CV-Risk Factors (\%) } \\
\hline Diabetes* & 6.2 \\
\hline Hypertension* & 47.3 \\
\hline Family history of CAD** & 26.9 \\
\hline Smoking** & 15 \\
\hline Body Mass Index (kg/m2) & $26.2(24.2-29.3)$ \\
\hline \multicolumn{2}{|l|}{ Laboratory profile } \\
\hline Total cholesterol (mg/dl) & $209(181.2-239)$ \\
\hline LDL cholesterol (mg/dl) & $125(96.7-151)$ \\
\hline HDL cholesterol (mg/dl) & $52(44-60)$ \\
\hline Triglycerides $(\mathrm{mg} / \mathrm{dl})$ & $14 \mid(103-197.5)$ \\
\hline C-reactive protein $(\mathrm{mg} / \mathrm{dl})$ & $0.23(0-0.53)$ \\
\hline Adiponectin (ug/ml) & $5.05(3.25-7.67)$ \\
\hline MMP-I (ng/ml) & $3.91(2.24-5.67)$ \\
\hline MMP-9 (ng/ml) & $211.3(147.1-283)$ \\
\hline \multicolumn{2}{|l|}{ Medical treatment (\%)**** } \\
\hline Statin & 37.7 \\
\hline Anticoagulation/Antiplatelet & 63.5 \\
\hline Betablocker & 64.9 \\
\hline ACE-I or ARB & 51.8 \\
\hline Diuretics & 30.6 \\
\hline \multicolumn{2}{|l|}{ CT data } \\
\hline Pericardial adipose tissue in volume $(\mathrm{ml}) \S$ & I84.I (I28.6-255.8) \\
\hline Number of coronary artery plaques (total)§§ & $3(1-6)$ \\
\hline Number of calcified plaques (I 54 patients) & $\mathrm{I}(0-3)$ \\
\hline Number of mixed plaques (102 patients) & $0(0-1)$ \\
\hline Number of non-calcified plaques (I 26 patients) & $0(0-2)$ \\
\hline
\end{tabular}

Anticoagulation: Aspirin, Clopidogrel, Phenprocoumon

Values are presented as proportions or median (interquartile range). Minimum/maximum values are presented for plaque data. No plaques were found in 51 patients.

* history of hypertension and diabetes is known in 236 patients

** history of smoking and family history of CAD is known in 235 patients

**** medical treatment is known in 222 patients

§adequate image quality for evaluation of PAT was obtained in 248 patients

$\S \S$ adequate image quality for evaluation of coronary plaques was obtained in 242 patients 


\section{Figure 1:}

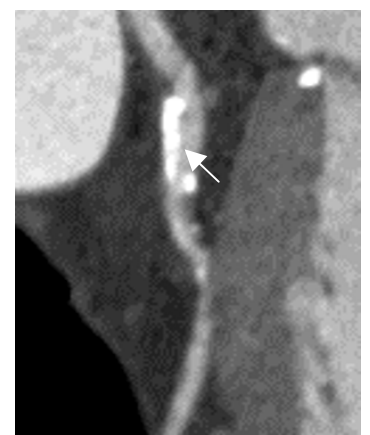

a) calcified plaque

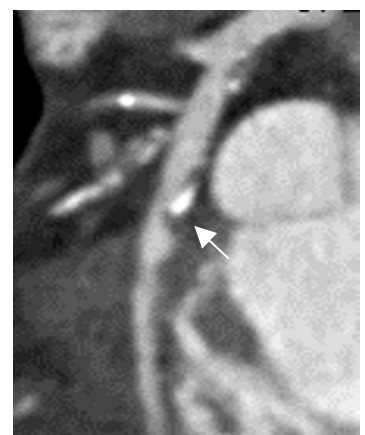

b) mixed plaque

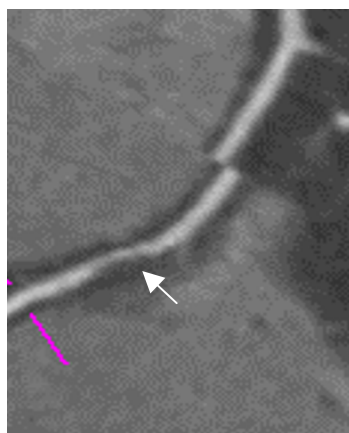

c) non-calcified plaque

Figure I

Representative images of calcified (a), mixed (b) and non-calcified plaques (c) as detected by CT-angiography.

lation of both MMPs were found with serum triglycerides (MMP-1, $\mathrm{r}=0.195, \mathrm{p}=0.002$; MMP-9, $\mathrm{r}=0.135, \mathrm{p}=$ 0.03 ), while only MMP-9 correlated to BMI ( $\mathrm{r}=0.149 ; \mathrm{p}$ $=0.02)$ and pericardial adipose tissue volume $(\mathrm{r}=0.253$; $\mathrm{p}<0.001$ ) (Table 2).

MMP-1 but not MMP-9 serum levels correlated with total plaque burden $(\mathrm{r}=0.16 ; \mathrm{p}=0.013)$ in addition to noncalcified lesions $(\mathrm{r}=0.157 ; \mathrm{p}=0.014)$ (Figure 2, Table 2).

No associations of either parameter were found with age, sex, total cholesterol, LDL-cholesterol, HDL-cholesterol, adiponectin, classical cardiovascular risk factors or medication, although patients receiving betablockers had lower MMP-9 levels ( $\mathrm{p}=0.049)$ (Table 2).

\section{MMP-I serum level predict total plaque burden}

In multivariable logistic regression analysis MMP-1 serum levels were associated with total plaque burden in a simple model adjusting for age, sex, BMI (OR 1.28 (CI: 1.02 to 1.59 ; $\mathrm{p}<0.05$ ) as well as in more complex models adjusting for all covariables (age, sex, BMI, classical cardiovascular risk factors, hsCRP, adiponectin, pericardial fat volume, medication) (OR 1.37 (CI: 1.02 to 1.85 ; $\mathrm{p}<0.05$ ) (Table 3). No association of MMP-9 was found with total plaque burden (Table 3 ).

\section{MMP-I serum levels predict calcified and non-calcified lesions}

To further evaluate the relevance of MMP-1 and MMP-9 serum levels to predict the presence of calcified, mixed or non-calcified plaques, a multivariable logistic regression analysis was performed for each parameter. Positive association of MMP-1 serum levels were found with calcified (OR 1.22 (CI: 1.04 to 1.43 ; p < 0.05), mixed (OR 1.19 (CI: 1.03 to $1.38 ; \mathrm{p}<0.049$ ), and non-calcified lesions (OR 1.19 (CI: 1.04 to 1.37 ; $\mathrm{p}<0.05$ ) after adjusting for age, sex, BMI and classical cardiovascular risk factors (Table 4). This association remained significant for calcified (OR 1.22 (CI: 1.03 to $1.45 ; \mathrm{p}<0.05$ ) and non-calcified (OR 1.16 (CI: 1.0 to $1.34 ; \mathrm{p}=0.05$ ) lesions after further adjustment for hsCRP, adiponectin, pericardial fat volume and medication but was lost for mixed lesions (Table 4). No association was found between MMP-9 serum levels and non-calcified, mixed or calcified lesions.

\section{Discussion}

In this study we report a positive association of MMP-1 serum levels with total plaque burden in a population of 260 patients who underwent CT-angiography for exclusion of coronary artery disease.

We thereby found MMP-1 serum levels to associate with calcified lesions and non-calcified lesions after adjustment for age, sex, BMI, classical cardiovascular risk factors, hsCRP, adiponectin, pericardial fat volume and medication. MMP-1 serum levels were further associated with mixed lesions in reduced statistical models, which was however lost after adjustment for all covariables.

Clinical risk management of cardiovascular disease would greatly benefit from event stratifying biomarkers. The rupture prone atherosclerotic plaque is histologically defined by a thin fibrous cap overlaying a lipid enriched atherom- 
Table 2: Correlation of Serum MMP-I and MMP-9 levels with cardio vascular risk factors and plaque morphology

\begin{tabular}{|c|c|c|c|c|c|}
\hline & & \multicolumn{2}{|c|}{ MMP-I } & \multicolumn{2}{|c|}{ MMP-9 } \\
\hline & & $\begin{array}{c}\text { Median (IQR) } \\
\text { Rho }\end{array}$ & $\mathbf{P}$ & $\begin{array}{c}\text { Median (IQR) } \\
\text { Rho }\end{array}$ & $\mathbf{P}$ \\
\hline Age & & -0.003 & 0.97 & 0.004 & 0.50 \\
\hline \multicolumn{6}{|l|}{ Sex } \\
\hline - female & & $4.46(2.24-5.69)$ & 0.6 & $207(137-169)$ & 0.16 \\
\hline - male & & $3.38(2.12-5.52)$ & & $220(160-288)$ & \\
\hline BMI & & 0.025 & 0.69 & 0.149 & 0.018 \\
\hline \multirow[t]{2}{*}{ Diabetes mellitus: } & Yes & $4.34(2.99-5.82)$ & 0.60 & $243.2(189.9-354.1)$ & 0.89 \\
\hline & No & $3.78(2.09-5.67)$ & & $209.6(\mid 44.8-277.2)$ & \\
\hline \multirow[t]{2}{*}{ Hypertension: } & Yes & $3.74(2.10-5.82)$ & 0.89 & $212.7(\mid 50.1-288 . I)$ & 0.67 \\
\hline & No & $3.96(2.23-5.67)$ & & $195.6(135.5-266.9)$ & \\
\hline \multirow[t]{2}{*}{ Family history of CAD: } & Yes & $3.73(1.80-5.64)$ & 0.45 & $195.6(\mid 40.4-268.4)$ & 0.15 \\
\hline & No & $3.93(2.24-5.69)$ & & $212.4(\mid 48.1-287.5)$ & \\
\hline \multirow[t]{2}{*}{ Smoking: } & Yes & $4.08(1.90-5.70)$ & 0.86 & $185.6(133.6-283.2)$ & 0.97 \\
\hline & No & $3.73(2.24-5.67)$ & & $212.3(\mid 46.0-275.8)$ & \\
\hline \multirow[t]{2}{*}{ Statin treatment: } & Yes & $4.11(2.44-5.90)$ & 0.25 & $205.2(|38.8-284|)$. & 0.44 \\
\hline & No & $3.52(2.09-5.65)$ & & $212.3(153.7-280.6)$ & \\
\hline \multirow[t]{2}{*}{ Anticoagulation: } & Yes & $3.71(2.18-5.65)$ & 0.32 & $180.9(137.0-257.5)$ & 0.06 \\
\hline & No & $3.67(2.02-5.61)$ & & $235.0(157.6-313.5)$ & \\
\hline \multirow[t]{2}{*}{ Betablocker: } & Yes & $3.91(2.44-5.23)$ & 0.80 & $206.5(139.5-273.5)$ & 0.049 \\
\hline & No & $3.48(2.07-6.07)$ & & $217.8(158.5-339.3)$ & \\
\hline \multirow[t]{2}{*}{ ACE-I or ARB: } & Yes & $4.11(2.44-5.65)$ & 0.51 & $207.6(144.7-283.2)$ & 0.66 \\
\hline & No & $3.5(2.09-5.82)$ & & $210.3(153.7-282.3)$ & \\
\hline \multirow[t]{2}{*}{ Diuretics: } & Yes & $4.06(2.90-5.59)$ & 0.32 & $211.8(141.3-300.0)$ & 0.76 \\
\hline & No & $3.6(2.07-5.79)$ & & $209.6(151.1-276.9)$ & \\
\hline Pericardial adipose tissue & & 0.068 & 0.28 & 0.253 & $<0.0001$ \\
\hline Adiponectin & & -0.1111 & 0.08 & -0.084 & 0.18 \\
\hline High-sensitivity CRP & & 0.194 & 0.001 & 0.173 & 0.005 \\
\hline Triglycerides & & 0.195 & 0.002 & 0.135 & 0.028 \\
\hline Total-cholesterol & & $0.04 I$ & 0.52 & -0.037 & 0.53 \\
\hline LDL-cholesterol & & -0.002 & 0.97 & -0.049 & 0.43 \\
\hline HDL-cholesterol & & -0.048 & 0.45 & -0.018 & 0.77 \\
\hline MMP-I & & & & 0.269 & $<0.0001$ \\
\hline Total-Plaque burden & & 0.16 & 0.013 & 0.087 & 0.17 \\
\hline Non-Calcified Plaques & & 0.157 & 0.014 & 0.002 & 0.98 \\
\hline Mixed Plaques & & 0.119 & 0.07 & 0.12 & 0.06 \\
\hline Calcified Plaques & & 0.118 & 0.07 & 0.058 & 0.37 \\
\hline
\end{tabular}

Median (IQR) or Spearman correlation coefficient are presented. (CAD: Coronary artery disease)

atous core [1]. Non-calcified, lipid enriched plaques have primarily been found in patients presenting with acute coronary syndrome and unstable angina, while mixed or calcified lesions dominated in patients with stable angina [3-6]. Consequently, non-calcified plaques were prospectively associated with increased coronary event rates [8,9], and short term tendency for plaque volume progression [17]. Non-calcified plaques have therefore been considered to be more prone to rupture than calcified lesions. Consistently, we did find MMP-1 serum levels to be posi- tively associated with non calcified lesions, however, similar associations were found with calcified- and to a lesser extent with mixed lesions, resulting in a positive association of MMP-1 serum levels with total plaque burden without discriminative power for a specific plaque morphology.

Evidence for plaque destabilising characteristics of MMP1 has been created by its accumulation in the vulnerable shoulder region of thin capped, lipid enriched plaques 


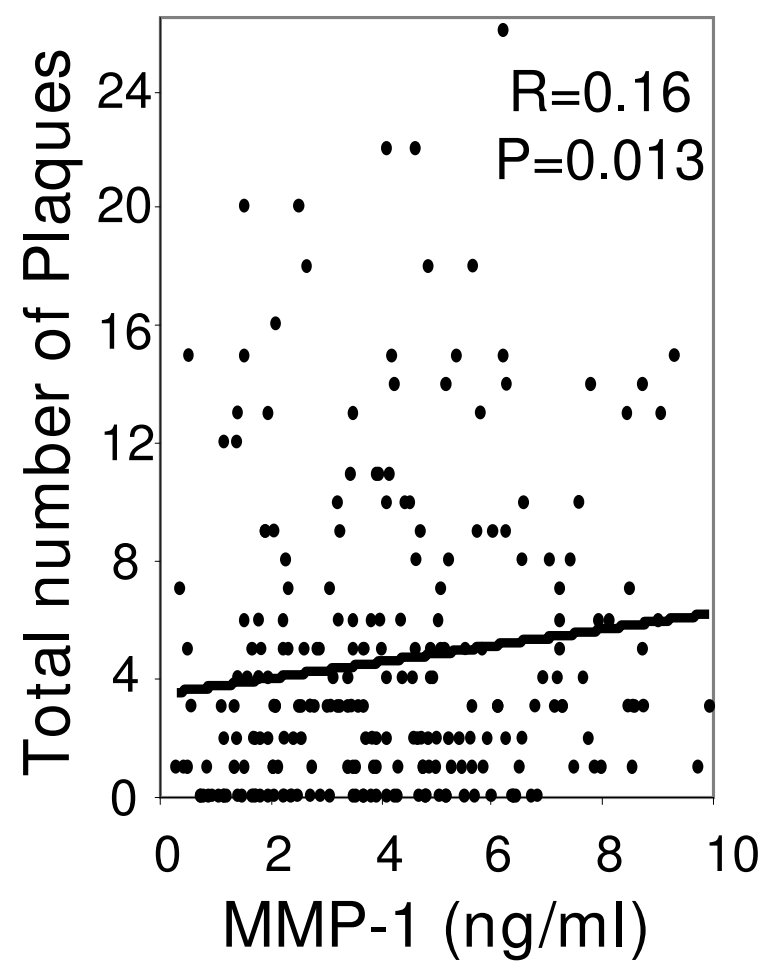

Figure 2

Correlation between MMP-I serum levels and total plaque burden.

and its co-localization with degraded collagen fragments $[10,11]$. In addition, increased serum levels of MMP-1 have been found in patients with coronary artery disease in some $[18,19]$, but not all studies [20], with highest levels being present in patients with unstable angina [21]. The positive association of MMP-1 serum levels with total plaque burden as reported in our study therefore supports the concept of MMP-1 being significantly released from atherosclerotic plaques. The missing discriminative power of MMP-1 serum levels for a specific plaque morphology however suggests MMP-1 to be similarly present within all plaques, independent of their morphology, questioning its relevance as a major plaque destabilizing factor. Alternatively, non-calcified lesions as determined by CT-angiography might not sufficiently identify the rupture prone vulnerable lesion. CT-angiography has been reported to provide a diagnostic sensitivity of 82 to $84 \%$ and specificity of 88 to $91 \%$ in comparison to IVUS as the gold standard $[22,23]$. Highest diagnostic accuracy was found for calcified lesions (sensitivity $94 \%$ to $95 \%$; specificity $92 \%$ to $94 \%$ ), while non-calcified lesions were detected with a diagnostic sensitivity of $78 \%$ by our group in a previous study and $53 \%$ by Achenbach et al. [22,23]. In addition, CT-angiography has limited capacities to further subdivide non-calcified lesions in fibrous and lipid enriched plaques. CT-angiography therefore provides an advanced non-invasive diagnostic tool for the detection of coronary plaques, which however still holds modest limitations in the detection of non-calcified lesions. We can not rule out that this might have affected the presented results.

MMP-1 and MMP-9 are primarily expressed by macrophages and smooth muscle cells in response to a variety of proatherogenic stimuli including sheer stress, oxidized LDL and inflammatory cytokines [10]. Consistently, circulating MMP-1 levels have been associated with atherosclerotic plaque inflammation as detected by 18F-FDGPET/CT [18]. In agreement with their proinflammatory regulation we found both MMPs to correlate positively with the inflammatory marker hsCRP. Our study therefore supports the concept of an inflammatory microenvironement characterising the atherosclerotic plaque which potentially could reflect plaque macrophage content. In contrast to other studies we could not ascribe highest inflammatory activity to non-calcified lesions [24,25]. Future studies are needed to characterise plaque morphology dependent inflammation in-vivo, preferentially by combining CT-Angiography with 18F-FDG-PET.

Surprisingly, we did not find associations between MMP9 serum levels and total plaque burden or plaque morphology. This agrees with some reports $[26,27]$ but con-

Table 3: Multivariate Association of MMP-I and MMP-9 serum levels and total plaque burden as assessed by CT-angiography

\begin{tabular}{|c|c|c|c|c|}
\hline \multirow{2}{*}{$\begin{array}{l}\text { Total Plaque } \\
\text { Adjusted for }\end{array}$} & \multicolumn{2}{|c|}{ MMP-I } & \multicolumn{2}{|c|}{ MMP-9 } \\
\hline & OR (CI) & P value & OR (CI) & $P$ value \\
\hline Age, Gender, BMI & 1.28 (1.02 to 1.59$)$ & 0.031 & $0.97(0.90$ to 1.05$)$ & 0.49 \\
\hline Age, Gender, BMI, RF* & $1.30(1.01$ to 1.66$)$ & 0.040 & $0.96(0.90$ to 1.03$)$ & 0.29 \\
\hline Age, Gender, BMI, RF*, CRP & $1.29(1.00$ to 1.67$)$ & 0.044 & $0.96(0.90$ to 1.03$)$ & 0.28 \\
\hline Age, Gender, BMI, RF*, CRP, AD, PCF & $1.32(1.01$ to 1.72$)$ & 0.040 & $0.97(0.90$ to 1.03$)$ & 0.32 \\
\hline Age, Gender, BMI, RF*, CRP, AD, PCF, Med & $1.37(1.02$ to 1.85$)$ & 0.037 & $0.98(0.90$ to 1.06$)$ & 0.63 \\
\hline
\end{tabular}

Odds ratio and $95 \% \mathrm{Cl}$ increase in plaque quantity for $\mathrm{I} \mathrm{ng} / \mathrm{ml}$ (MMP-I) and $20 \mathrm{ng} / \mathrm{ml}$ (MMP-9) raise in serum levels are presented.

*Risk factors (RF*) included LDL-cholesterol, HDL-cholesterol, triglycerides, cigarette smoking, hypertension, diabetes, family history for CVD. Abbreviations: CRP (hsCRP), AD (adiponectin), PCF (pericardial fat volume), Med (medication) 
Table 4: Multivariate Association of MMP-I and MMP-9 serum levels and quantity of non-calcified, mixed and calcified plaques as assessed by CT-angiography

Non-calcified Plaque

MMP-I

MMP-9

\begin{tabular}{|c|c|c|c|c|}
\hline Adjusted for & OR (Cl) & $P$ value & OR (Cl) & P value \\
\hline Age, Gender, BMI & 1.19 (1.04 to 1.37$)$ & 0.012 & 0.99 (0.95 to 1.04$)$ & 0.74 \\
\hline Age, Gender, BMI, RF* & 1.19 (1.03 to 1.37$)$ & 0.017 & $0.99(0.95$ to 1.04$)$ & 0.76 \\
\hline Age, Gender, BMI, RF*, CRP & 1.20 (I.04 to I.38) & 0.014 & I (0.95 to I.05) & 0.90 \\
\hline Age, Gender, BMI, RF*, CRP, AD, PCF & 1.18 (1.03 to 1.37$)$ & 0.021 & $0.99(0.94$ to 1.04$)$ & 0.80 \\
\hline Age, Gender, BMI, RF*, CRP, AD, PCF, Med & $1.16(1.00$ to 1.34$)$ & 0.050 & I (0.95 to I.05) & 0.90 \\
\hline Mixed Plaque & \multicolumn{2}{|l|}{ MMP-I } & \multicolumn{2}{|l|}{ MMP-9 } \\
\hline Adjusted for & OR (Cl) & P value & OR (CI) & $P$ value \\
\hline Age, Gender, BMI & 1.19 (1.03 to 1.38$)$ & 0.019 & 0.99 (0.94 to 1.04$)$ & 0.71 \\
\hline Age, Gender, BMI, RF* & $1.19(1.02$ to 1.39$)$ & 0.014 & $0.99(0.94$ to 1.04$)$ & 0.77 \\
\hline Age, Gender, BMI, RF*, CRP & 1.19 ( 1.02 to 1.39$)$ & 0.024 & 0.99 (0.94 to 1.05$)$ & 0.79 \\
\hline Age, Gender, BMI, RF*, CRP, AD, PCF & 1.17 ( 1.00 to 1.37$)$ & 0.047 & 0.99 (0.94 to 1.04$)$ & 0.67 \\
\hline Age, Gender, BMI, RF*, CRP, AD, PCF, Med & 1.14 (0.96 to 1.35$)$ & 0.12 & $0.99(0.94$ to 1.05$)$ & 0.83 \\
\hline Calcified Plaque & \multicolumn{2}{|l|}{ MMP-I } & \multicolumn{2}{|l|}{ MMP-9 } \\
\hline Adjusted for & OR (Cl) & P value & OR (Cl) & P value \\
\hline Age, Gender, BMI & $1.22(1.04$ to 1.43$)$ & 0.013 & $0.99(0.94$ to 1.05$)$ & 0.78 \\
\hline Age, Gender, BMI, RF* & $1.22(1.04$ to 1.43$)$ & 0.016 & $0.98(0.93$ to 1.04$)$ & 0.69 \\
\hline Age, Gender, BMI, RF*, CRP & 1.21 (1.03 to 1.42$)$ & 0.020 & $0.98(0.93$ to 1.04$)$ & 0.49 \\
\hline Age, Gender, BMI, RF*, CRP, AD, PCF & 1.21 ( 1.03 to 1.43$)$ & 0.019 & $0.98(0.94$ to 1.05$)$ & 0.57 \\
\hline Age, Gender, BMI, RF*, CRP, AD, PCF, Med & $1.22(1.03$ to 1.45$)$ & 0.023 & $0.98(0.9 w$ to 1.05$)$ & 0.64 \\
\hline
\end{tabular}

Odds ratio and $95 \% \mathrm{Cl}$ increase in plaque quantity for I $\mathrm{ng} / \mathrm{ml}$ (MMP-I) and $20 \mathrm{ng} / \mathrm{ml}$ (MMP-9) raise in serum levels are presented.

*Risk factors (RF*) included LDL-cholesterol, HDL-cholesterol, triglycerides, cigarette smoking, hypertension, diabetes, family history for CVD.

Abbreviations: CRP (hsCRP), AD (adiponectin), PCF (pericardial fat volume), Med (medication)

trasts to others, which found incremental MMP-9 serum levels in patients with coronary artery disease $[28,29]$. The reason for this discrepancy is not clear but might be related to different patient populations and a differential assessment of atherosclerosis. CT angiography as used in our study allows the assessment of non-stenosing, outward directed lesions of the vessel wall and is not limited to the detection of stenosing lesions as assessed by coronary angiography [30].

Interestingly and consistent with others we found positive association between MMP-9 serum levels and BMI $[31,32]$, in addition to pericardial fat volume and serum triglyceride concentrations, suggesting adipose tissue to be a significant determinant of circulating MMP-9 levels.

Our study has several limitations. Detection of coronary plaques quantity and morphology by CT-angiography does not provide the diagnostic accuracy of IVUS as the gold standard. The presented results are associative and can not prove causal relationship between MMP-1 serum levels and atherosclerotic plaque quantity or morphology. In addition, the cross sectional study design did not allow an evaluation of clinical relevance with respect to future cardiac event rates. Future studies are needed to confirm our findings in larger patient cohorts possibly by applying a prospective study design.

In conclusion we found MMP-1 serum levels to be an independent predictor for coronary atherosclerotic lesions, while not allowing a stratification of plaque morphology.

\section{Competing interests}

The authors declare that they have no competing interests.

\section{Authors' contributions}

ML: study design, data analysis, manuscript preparation, MG: study design, data analysis, manuscript editing, UCB: study design, manuscript editing, CL: data acquisition, 
manuscript editing, RPL: statistical analysis, AB: study design, manuscript editing, FvZ: data analysis, manuscript editing, MR: final approval of the manuscript, $\mathrm{CB}$ : data acquisition, BG: final approval of the manuscript, GS: final approval of the manuscript, AWL: study design, manuscript editing, KGP: study design, manuscript editing. All authors read and approved the final manuscript.

\section{Acknowledgements}

We are indebted to Elisabeth Fleischer-Brielmaier, Inge Biller-Friedmann and Kerstin Henze for expert technical assistance.

\section{References}

I. Schaar JA, Muller JE, Falk E, Virmani R, Fuster V, Serruys PW Colombo A, Stefanadis C, Ward Casscells S, Moreno PR, Maseri A Steen AF van der: Terminology for high-risk and vulnerable coronary artery plaques. Report of a meeting on the vulnerable plaque, June 17 and 18, Santorini, Greece. Eur Heart J 2003, 25: 1077-82.

2. Stary HC, Chandler AB, Dinsmore RE, Fuster V, Glagov S, Insull W Jr, Rosenfeld ME, Schwartz CJ, Wagner WD, Wissler RW: A definition of advanced types of atherosclerotic lesions and a histological classification of atherosclerosis. A report from the Committee on Vascular Lesions of the Council on Arteriosclerosis, American Heart Association. Circulation 1995, 92:1355-74.

3. Hoffmann U, Moselewski F, Nieman K, Jang IK, Ferencik M, Rahman AM, Cury RC, Abbara S, Joneidi-Jafari H, Achenbach S, Brady T]: Noninvasive assessment of plaque morphology and composition in culprit and stable lesions in acute coronary syndrome and stable lesions in stable angina by multidetector computed tomography. J Am Coll Cardiol 2006, 47:1655-62.

4. Leber AW, Knez A, White CW, Becker A, von Ziegler F, Muehling O, Becker C, Reiser M, Steinbeck G, Boekstegers P: Composition of coronary atherosclerotic plaques in patients with acute myocardial infarction and stable angina pectoris determined by contrast-enhanced multislice computed tomography. Am J Cardiol 2003, 9 1:7|4-8.

5. Feuchtner G, Postel T, Weidinger F, Frick M, Alber H, Dichtl W, Jodocy D, Mallouhi A, Pachinger O, Zur Nedden D, Friedrich G]: Is there a relation between non-calcifying coronary plaques and acute coronary syndromes? A retrospective study using multislice computed tomography. Cardiology 2008, I I 0:24 I-8.

6. Henneman MM, Schuijf JD, Pundziute G, van Werkhoven JM, Wall EE van der, Jukema JW, Bax J]: Noninvasive evaluation with multislice computed tomography in suspected acute coronary syndrome: plaque morphology on multislice computed tomography versus coronary calcium score. J Am Coll Cardiol 2008, 52:216-22.

7. Huang $H$, Virmani R, Younis $H$, Burke AP, Kamm RD, Lee RT: The impact of calcification on the biomechanical stability of atherosclerotic plaques. Circulation 2001, 103:105I-6.

8. Cohen A, Tzourio C, Bertrand B, Chauvel C, Bousser MG, Amarenco $P$ : Aortic plaque morphology and vascular events: a follow-up study in patients with ischemic stroke. FAPS Investigators. French Study of Aortic Plaques in Stroke. Circulation 1997 96:3838-4I.

9. Yamagishi M, Terashima M, Awano K, Kijima M, Nakatani S, Daikoku S, Ito K, Yasumura Y, Miyatake K: Morphology of vulnerable coronary plaque: insights from follow-up of patients examined by intravascular ultrasound before an acute coronary syndrome. J Am Coll Cardiol 2000, 35: I06-II

10. Newby AC: Metalloproteinase expression in monocytes and macrophages and its relationship to atherosclerotic plaque instability. Arterioscler Thromb Vasc Biol 2008, 28:2I08-I4.

II. Sukhova GK, Schonbeck U, Rabkin E, Schoen FJ, Poole AR, Billinghurst RC, Libby $P$ : Evidence for increased collagenolysis by interstitial collagenases-I and -3 in vulnerable human atheromatous plaques. Circulation 1999, 99:2503-9.

12. Visse $R$, Nagase $H$ : Matrix metalloproteinases and tissue inhibitors of metalloproteinases: structure, function, and biochemistry. Circ Res 2003, 92:827-39.
13. Zhang B, Ye S, Herrmann SM, Eriksson P, de Maat M, Evans A, Arveiler D, Luc G, Cambien F, Hamsten A, Watkins H, Henney AM: Functional polymorphism in the regulatory region of gelatinase $B$ gene in relation to severity of coronary atherosclerosis. Circulation 1999, 99:1788-94.

14. Pearce E, Tregouet DA, Samnegard A, Morgan AR, Cox C, Hamsten A, Eriksson $P$, Ye S: Haplotype effect of the matrix metalloproteinase-I gene on risk of myocardial infarction. Circ Res 2005, 97:1070-6.

15. Broedl UC, Lebherz C, Lehrke M, Stark R, Greif M, Becker A, von Ziegler F, Tittus J, Reiser M, Becker C, Göke B, Parhofer KG, Leber AW: Low adiponectin levels are an independent predictor of mixed and non-calcified coronary atherosclerotic plaques. PLOS ONE 2009, 4:e4733.

16. Greif M, Becker A, von Ziegler F, Lebherz C, Lehrke M, Broedl UC Tittus J, Parhofer K, Becker C, Reiser M, Knez A, Leber AW: Pericardial adipose tissue determined by dual source $C T$ is a risk factor for coronary atherosclerosis. Arterioscler Thromb Vasc Biol 2009, 29:781-6.

17. Leber AW, von Ziegler F, Becker A, Becker CR, Reiser M, Steinbeck G, Knez A, Boekstegers P: Characteristics of coronary plaques before angiographic progression determined by Multi-Slice CT. Int I Cardiovasc Imaging 2008, 24:423-8.

18. Wu YW, Kao HL, Chen MF, Lee BC, Tseng WY, Jeng JS, Tzen KY, Yen RF, Huang PJ, Yang WS: Characterization of plaques using I 8F-FDG PET/CT in patients with carotid atherosclerosis and correlation with matrix metalloproteinase-I. J Nucl Med 2007, 48:227-33.

19. Hwang JJ, Yang WS, Chiang FT, Chen MF, Lin HJ, Huang PJ, Hsu SH, Lai SK, Wu YW: Association of circulating matrix metalloproteinase-I, but not adiponectin, with advanced coronary artery disease. Atherosclerosis 2009, 204:293-7.

20. Kato R, Momiyama $Y$, Ohmori R, Taniguchi H, Nakamura H, Ohsuzu F: Plasma matrix metalloproteinase- 8 concentrations are associated with the presence and severity of coronary artery disease. Circ J 2005, 69:1035-40.

21. Inoue T, Kato T, Takayanagi K, Uchida T, Yaguchi I, Kamishirado H, Morooka S, Yoshimoto N: Circulating matrix metalloproteinase-I and -3 in patients with an acute coronary syndrome. Am J Cardiol 2003, 92: | 46 I-4.

22. Achenbach S, Moselewski F, Ropers D, Ferencik M, Hoffmann U, MacNeill B, Pohle K, Baum U, Anders K, Jang IK, Daniel WG, Brady T]: Detection of calcified and noncalcified coronary atherosclerotic plaque by contrast-enhanced, submillimeter multidetector spiral computed tomography: a segment-based comparison with intravascular ultrasound. Circulation 2004, 109:14-7.

23. Leber AW, Knez A, Becker A, Becker C, von Ziegler F, Nikolaou K Rist C, Reiser M, White C, Steinbeck G, Steinbeck G, Boekstegers P: Accuracy of multidetector spiral computed tomography in identifying and differentiating the composition of coronary atherosclerotic plaques: a comparative study with intracoronary ultrasound. I Am Coll Cardiol 2004, 43: I24|-7.

24. Hausleiter J, Meyer T, Hadamitzky M, Kastrati A, Martinoff S, Schomig A: Prevalence of noncalcified coronary plaques by 64-slice computed tomography in patients with an intermediate risk for significant coronary artery disease. J Am Coll Cardiol 2006, 48:312-8.

25. Sawada T, Shite J, Shinke T, Watanabe $S$, Otake $H$, Matsumoto $D$ Tanino Y, Ogasawara D, Paredes OL, Yokoyama M: [Relationship between high sensitive $\mathrm{C}$-reactive protein and coronary plaque component in patients with acute coronary syndrome: Virtual Histology study]. J Cardiol 2006, 48: I 4I-50.

26. Welsh $\mathrm{P}$, Whincup $\mathrm{PH}$, Papacosta O, Wannamethee SG, Lennon L, Thomson A, Rumley A, Lowe GD: Serum matrix metalloproteinase-9 and coronary heart disease: a prospective study in middle-aged men. Ojm 2008, 101:785-91.

27. Tziakas DN, Lazarides MK, Tentes IK, Georgiadis GS, Eleftheriadou E, Chalikias GK, Kortsaris A, Hatseras DI: Gelatinases [matrix metalloproteinase-2 (MMP-2) and MMP-9] induce carotid plaque instability but their systemic levels are not predictive of local events. Ann Vasc Surg 2005, 19:529-33.

28. Tayebjee MH, Lip GY, Tan KT, Patel JV, Hughes EA, MacFadyen RJ: Plasma matrix metalloproteinase-9, tissue inhibitor of metalloproteinase-2, and CD40 ligand levels in patients with stable coronary artery disease. Am J Cardiol 2005, 96:339-45. 
29. Blankenberg S, Rupprecht HJ, Poirier O, Bickel C, Smieja M, Hafner G, Meyer J, Cambien F, Tiret L: Plasma concentrations and genetic variation of matrix metalloproteinase 9 and prognosis of patients with cardiovascular disease. Circulation 2003, 107:1579-85.

30. Mintz GS, Painter JA, Pichard AD, Kent KM, Satler LF, Popma JJ, Chuang YC, Bucher TA, Sokolowicz LE, Leon MB: Atherosclerosis in angiographically "normal" coronary artery reference segments: an intravascular ultrasound study with clinical correlations. J Am Coll Cardiol 1995, 25:1479-85.

31. Derosa G, Ferrari I, D'Angelo A, Tinelli C, Salvadeo SA, Ciccarelli L, Piccinni MN, Gravina A, Ramondetti F, Maffioli P, Cicero AF: Matrix metalloproteinase-2 and -9 levels in obese patients. Endothelium 2008, 15:219-24.

32. Kosmala W, Plaksej R, Przewlocka-Kosmala M, Kuliczkowska-Plaksej J, Bednarek-Tupikowska G, Mazurek W: Matrix metalloproteinases 2 and 9 and their tissue inhibitors $I$ and 2 in premenopausal obese women: relationship to cardiac function. Int J Obes (Lond) 2008, 32:763-7I.

Publish with Bio Med Central and every scientist can read your work free of charge

"BioMed Central will be the most significant development for disseminating the results of biomedical research in our lifetime. "

Sir Paul Nurse, Cancer Research UK

Your research papers will be:

- available free of charge to the entire biomedical community

- peer reviewed and published immediately upon acceptance

- cited in PubMed and archived on PubMed Central

- yours - you keep the copyright

Submit your manuscript here:

http://www.biomedcentral.com/info/publishing_adv.asp 